\title{
DYNAMICS OF VITREOUS AND MOLTEN ZINC CHLORIDE
}

\author{
David L. Price, Marie Louise Saboungi, Sherman Susman \\ Kenneth J. Volin, and Adrian C. Wright* \\ Materials Science Division \\ Argonne National Laboratory \\ Argonne, IL 60439
}

ANL/CP- -73443

\section{DISCLAIMER}

\begin{abstract}
This report was prepared as an account of work sponsored by an agency of the United States Government. Neither the United States Government nor any agency thereof, nor any of their employees, makes any warranty, express or implied, or assumes any legal liability or respunsibility for the accuracy, completeness, or usefulness of any information, apparatus, product, or process disclosed, or represents that its use would not infringe privately owned rights. Reference herein to any specific commercial product, process or service by trade name, trademark, manufacturer, or otherwise does not necessarily constitute or imply its endorsement, recommendation, or favoring by the United States Government or any agency thereof. The views and opinions of authors expressed herein do not necessarily state or reflect those of the United States Government or any agency thereof.
\end{abstract}

To be published in J. Non-Cryst. Solids

September, 1991

$/ \mathrm{sm}$

Distribution:

1-3. D. Hamrin

4. B. D. Dunlap

5. M. B. Brodsky

6. J. D. Jorgensen

7. B. S. Brown

8. Editorial Office

9. Authors

*J. J. Thomson Physical Laboratory, University of Reading, U.K.

Invited Paper for the 5th International Conference on Structure of Non-Crystalline Materials, Sendai, Japan, Sept. 2-6, 1991

This work is supported by the U.S. Department of Energy, Basic Energy Sciences, Materials Sciences, under contract No. W-31-109-ENG-38. 


\author{
David L. Price, Marie Louise Saboungi, Sherman Susman \\ Kenneth J. Volin, and Adrian C. Wright ${ }^{*}$ \\ Materials Science Division \\ Argonne National Laboratory \\ Argonne, IL 60439
}

To be published in J. Non-Cryst. Solids

September, 1991

$/ \mathrm{sm}$

*J. J. Thomson Physical Laboratory, University of Reading, U.K.

Invited Paper for the 5th International Conference on Structure of Non-Crystalline Materials, Sendai, Japan, Sept. 2-6, 1991

This work is supported by the U.S. Department of Energy, Basic Energy Sciences, Materials Sciences, under contract No. W-31-109-ENG-38. 
DYNAMICS OF VITREOUS AND MOLTEN ZINC CHLORIDE

DAVID L. PRICE, MARIE-LOUISE SABOUNGI, SHERMAN SUSMAN, KENNETH J. VOLIN AND ADRIAN C. WRIGHT*

Argonne National Laboratory

Argonne, IL 60439, USA

Submitted to the 5th International Conference on

Structure of Non-Crystalline Materials,

Sendai, Japan, September 2-6, 1991

To be published in J. Non-Cryst. Solids

${ }^{*}$ J. J. Thomson Physical Laboratory, University of Reading, U.K. 
DYNAMICS OF VITREOUS AND MOLTEN ZINC CHLORIDE

DA VID L. PRICE, MARIE-LOUISE SABOUNGI, SHERMAN SUSMAN, KENNETH

J. VOLIN and ADRIAN C. WRIGHT*

Argonne National Laboratory, Argonne, IL 60439, USA

The dynamics of vitreous and molten zinc chloride have been studied with inelastic neutron scattering at the Intense Pulsed Neutron Source. The results are analyzed in terms of the scattering function $S(Q, E)$ and the effective vibrational density of states $G(E)$. The vibrational spectra of both glass and liquid are dominated by broad features centered at 15 and $35 \mathrm{meV}$ which are identified with $\mathrm{F}_{2}$ modes of $\mathrm{ZnCl}_{4}{ }^{2-}$ tetrahedra. The other two normal modes are not observed because of inadequate resolution and broadening and overlap resulting from coupling between tetrahedra. The behavior of $\mathrm{ZnCl}_{2}$ is contrasted with other tetrahedrally coordinated glasses that have been studied with the same technique.

Zinc chloride, $\mathrm{ZnCl}_{2}$, has a tetrahedrally coordinated network structure in both vitreous and liquid states. Its structure has been thoroughly established by neutron diffraction measurements in the glass by Desa et al..$^{1}$ and in the liquid by Biggin and Enderby'a and by Howe et $\underline{\mathrm{al}}{ }^{2 \mathrm{~b}}$. It has also been investigated by Molecular Dynamics simulations ${ }^{3}$, on the basis of solely ionic forces. Its bond angle of approximately $110^{\circ} 1$ places it intermediate between oxide glasses like $\mathrm{SiO}_{2}\left(\sim 150^{\circ}\right)^{4}$ and chalcogenide glasses like $\mathrm{GeSe}_{2}\left(80-100^{\circ}\right)^{5}$ and $\operatorname{SiSe}_{2}\left(\sim 70^{\circ}\right)^{6}$. Relevant parameters for these glasses are listed in Table 1. From the point of view of transport properties, $\mathrm{ZnCl}_{2}$ behaves as a relatively fragile liquid ${ }^{7}$ compared with other tetrahedrally coordinated glass formers, having a rapid drop in viscosity as the temperature is raised above the glass transition, $\mathrm{T}_{\mathrm{g}}(390 \mathrm{~K})$.

The aims of the present study were to investigate the dynamics of the glass and liquid by measuring the scattering function $S(Q, E)$ over a wide range of energy $E$ and wave vector $Q$ and to compare the results with those of similar studies of vitreous $\mathrm{SiO}_{2}{ }^{8}, \mathrm{GeSe}_{2}{ }^{9}$, and $\mathrm{SiSe}_{2}{ }^{10}$. In addition, the low $\mathrm{T}_{\mathrm{g}}$ of $\mathrm{ZnCl}_{2}$ makes the liquid state more amenable to inelastic neutron scattering measurements than in the case of other tetrahedrally coordinated materials.

\footnotetext{
*Permanent address: J. J. Thomson Physical Laboratory University of Reading, U.K.
} 
Inelastic neutron scattering measurements on anhydrous $\mathrm{ZnCl}_{2}$ were carried out on the Low-Resolution Medium-Energy Chopper Spectrometer (LRMECS) at IPNS with an incident energy $\mathrm{E}_{0}=80.3 \mathrm{meV}$. Time-of-flight data were collected in 41 groups of detectors placed at mean scattering angles $\phi$ ranging from $2.7^{\circ}$ to $116.4^{\circ}$. Runs were made with the $\mathrm{ZnCl}_{2}$ sample in the vitreous state at $298 \mathrm{~K}$ and in the liquid state at $620 \mathrm{~K}$. This temperature, 230 $\mathrm{K}$ above the glass transition and $30 \mathrm{~K}$ above the melting point, $\mathrm{T}_{\mathrm{m}}=590 \mathrm{~K}$, was chosen to avoid the possibility of crystallization. Runs were also made with an equivalent set of empty silica tubes at the same temperatures, with a vanadium standard, with no material in the beam and with a cadmium absorber covering the sample. Data were converted to the form of the scattering function $S(Q, E)$ and effective vibrational density of states $G(E)$ using standard procedures described in detail in Ref. 8. The energy resolution (FWHM) was $5.3 \mathrm{meV}$ for elastic scattering $(E=0)$, decreasing to approximately $3.2 \mathrm{meV}$ for energy transfers of 50 $\mathrm{meV}$. The $\mathrm{Q}$ resolution was estimated to be $0.14 \AA^{-1}$ at $\mathrm{Q}=5 \AA^{-1}$.

Fig. 1 shows the elastic scattering, $S(Q, 0)$, for the glass and liquid as a function of $Q$. The general behavior is similar to that of the structure factors measured for the glass ${ }^{1}$ and liquid 2 by neutron diffraction, the main difference being the fall-off in the intensity at large $Q$, due to the larger proportion of scattering occurring at larger $E$ as $Q$ increases.

The energy dependence of the inelastic scattering is most easily visualized from the effective neutron- and amplitude-weighted vibrational density of states $G(E)^{8}$. For the glass, multi-phonon scattering was subtracted with an iterative procedure 8 to give the function $\mathrm{G}_{1}(\mathrm{E})$ shown in Fig. 2 , which represents the best estimate of the effective one-phonon density of states for the glass. The low-E region, where the elastic scattering falls within the resolution function, has been excluded. $G_{1}(E)$ is seen to be dominated by two peaks centered approximately at 15 and $35 \mathrm{meV}\left(\sim 120\right.$ and $280 \mathrm{~cm}^{-1)}$ respectively. The same two features were observed by Galeener et al. ${ }^{11}$ using a beryllium-filer spectrometer although the first peak occurs at a slightly lower energy $(\sim 11 \mathrm{meV})$ in their data.

In the Raman scattering data of Galeener et al. ${ }^{11}$, the spectrum with $\mathrm{HV}$ polarization, which usually resembles the true density of states ${ }^{12}$, shows principal peaks at 110 and 280 $\mathrm{cm}^{-1}$, in good agreement with the peaks in the neutron measurement. Smaller peaks are observed around 80,230 and $320 \mathrm{~cm}^{-1}$; the peak at $230 \mathrm{~cm}^{-1}$ dominates the $\mathrm{HH}$ spectrum. By analogy with $\mathrm{GeSe}_{2}{ }^{9}$, which has a iatner similar spectrum, the latter can be identified with the $A_{1}$ tetrahedral breathing mode. Peaks at similar energies are observed in the later measurements of Cacciola et al. ${ }^{13}$, who identify the peaks around 70, 100-120, 230 and 270- 
$320 \mathrm{~cm}^{-1}$ in the glass with tetrahedral modes of $E\left(v_{2}\right), F_{2}\left(v_{4}\right), A_{1}\left(v_{1}\right)$, and $F_{2}\left(v_{3}\right)$ symmetry, respectively. The spliting of the two $F_{2}$ modes is ascribed to TO-LO splitting. In the neutron effective density of states, only the two $F_{2}$ modes appear to be present. The same features, slightly shifted, are observed in the Raman spectra of the liquid at 592K.

The far-infrared spectra measured by Angell et al. ${ }^{14}$ for $\mathrm{ZnCl}_{2}$ glass and liquid show features generally similar to the Raman spectra. In the glass at room temperature, the principal peaks are at 105 and $265 \mathrm{~cm}^{-1}$ with shoulders at 75 and $120 \mathrm{~cm}^{-1}$; in the liquid at $593 \mathrm{~K}$, the principal peaks are at 90 and $260 \mathrm{~cm}^{-1}$ with a shoulder around $120 \mathrm{~cm}^{-1}$. The main difference from the Raman spectra is that the several Raman peaks observed in the $230-320 \mathrm{~cm}^{-1}$ region in both glass and liquid are replaced by $n$ oroad spectrum centered around $260 \mathrm{~cm}^{-1}$.

Sen and Thorpe ${ }^{15}$ have shown that, under a certain set of simplifying conditions, the aynamics of $\mathrm{AX}_{2}$ glasses can be described in terms of the $\mathrm{AX}_{4}$ tetrahedra. A necessary condition for this to be applicable is that the AXA bond angle $\theta$ lie below the critical value $\theta_{c}=\operatorname{os}^{-1}\left(-2 \mathrm{MX}_{X} / 3 \mathrm{M}_{\mathrm{A}}\right)$, which has the value $111^{\circ}$ for $\mathrm{ZnCl}_{2}$, very close to the observed value of $\theta$. If we adopt this approach nevertheless, the frequencies and structure factors of the normal modes can be calculated in terms of isolated $\mathrm{AX}_{4}$ tetrahedra following the procedure followed for $\mathrm{GeSe}_{2}$ in Ref. 9. With values for the two valence force constants of $\mathrm{f}_{1}{ }^{\prime \prime}=110$ and $\mathrm{f}_{2}{ }^{\prime \prime}=30 \mathrm{~N} / \mathrm{m}$, we obtain frequencies for the four tetrahedral modes of 104 (E), 112 $\left(F_{2}\right), 230\left(A_{1}\right)$ and $310\left(F_{2}\right) \mathrm{cm}^{-1}$, respectively, in reasonable agreement with the optical frequencies and with the two neutron peaks if these are ascribed to the two modes of $F_{2}$ symmetry. We discuss below the structure factors of these two modes.

Fig. 3 shows the total effective density of states $G(E)$ for the liquid, which is related to the Fourier transform of the weighted average velocity autocorrelation function. In spite of the difference in the state of the sample, the functions shown in Figs. 2 and 3 have some similarity. In particular, the features at 15 and $35 \mathrm{meV}$ observed in the glass survive the melting process, confirming the conclusion of Biggin and Enderby that the $\mathrm{ZnCl}_{4}{ }^{2-}$ tetrahedra continue to play a significant role in the structure of the liquid.

The wave-vector dependence of the inelastic scattering is best viewed by considering the $Q$ dependence of $S(Q, E)$ for a particular energy $E$. For the present purpose, we examine the scattering associated with the main peaks in $G(E)$. Figs. 4 and 5 show the $Q$ dependence of $S(Q, E)$ for the glass at energies $E=15.9$ and $35.6 \mathrm{meV}$, respectively. The $Q$ dependence shows the expected $Q^{2}$ dependence at small $Q$, followed by the drop-off at high $Q$ arising 
from the Debye-Waller factor, with a small amount of short-period oscillation, which can be ascribed to correlated displacements of nearby atoms in the normal modes of vibration 8,9 . In Figs. 4 and 5 we show the structure factors for the $F_{2}\left(v_{4}\right)$ and $F_{2}\left(v_{3}\right)$ modes computed with the tetrahedral model discussed above. There are some similarities between the observed and calculated structure factors, but the agreement is not as striking as in the case of $\mathrm{GeSe}_{2}{ }^{9}$, perhaps because the condition for the validity of the isolated tetrahedral model $\left(\theta<<\theta_{c}\right)$ is not as well fulfilled. We note that $\mathrm{SiSe}_{2}{ }^{10}$ also does not agree as well with the isolated tetrahedral model, perhaps because the tetrahedra are predominantly edge-sharing and therefore more strongly coupled. For $\mathrm{SiO}_{2}$, on the other hand, $\theta>\theta_{\mathrm{c}}$ and the dynamics are more suitably discussed in terms of $\mathrm{OSi}_{2}$ units 8 .

The value of the bond angle in $\mathrm{ZnCl}_{2}$ may account for the fact that only two peaks are visible in density of states $G_{1}(E)$ as measured by neutron scattering, compared with the four or more observed for $\mathrm{GeSe}_{2}{ }^{9}$. Sen and Thorpe ${ }^{15}$ showed that, as $\theta$ approaches $\theta_{c}$, the $v_{1}\left(A_{1}\right)$ and $v_{3}\left(F_{2}\right)$ tetrahedral modes broaden and in fact overlap at $\theta=\theta_{c}$, the condition which applies for $\mathrm{ZnCl}_{2}$. In particular, the delta-function component of the $v_{1}\left(A_{1}\right)$ mode overlaps with the continuous component of the $v_{3}\left(F_{2}\right)$. This appears to make the $v_{1}\left(A_{1}\right)$ mode indistinguishable in the neutron density of states. The lower two tetrahedral modes, $E\left(v_{2}\right)$ and $F_{2}\left(v_{4}\right)$ are, according to the optical data 12,13 , separated by about $30 \mathrm{~cm}^{-1}$ which is less than the resolution of the present measurement. The shoulder which can be barely identified in the neutron density of states at $11 \mathrm{meV}\left(90 \mathrm{~cm}^{-1}\right)$ may be an indication of the $\mathrm{E}\left(\mathrm{v}_{2}\right)$.

In conclusion, the vibrational spectra of both vitreous and liquid $\mathrm{ZnCl}_{2}$ are dominated by broad features centered at 15 and $35 \mathrm{meV}$. Taking into consideration the optical data and the $Q$ dependence of the structure factors at these energies, these features are ascribed to the two $\mathrm{F}_{2}$ modes of the $\mathrm{ZnCl}_{4}{ }^{2-}$ tetrahedra. The other two normal modes are not observed, the lower one possibly due to inadequate resolution, the upper one due to broadening and overlap resulting from coupling between tetrahedra, which is expected to be strong because the bond angle is nearly equal to the critical angle for inter-tetrahedral coupling.

We wish to thank R. Kleb for design and construction of the cartridge heater furnace, $T$. Brumleve of APL Engineering Materials Inc. for providing high quality, anhydrous material, and the operations staff of the Intense Pulsed Neutron Source for experimental assistance. 
We acknowledge helpful discussions with C. A. Angell, J. M. Carpenter, J. E. Enderby, C.-K. Loong, R. McGreevy and R. O. Pohl. This work was performed under the auspices of the U.S. Department of Energy, Division of Materials Science, Office of Basic Energy Sciences, under Contract W-31-109-ENG-38.

\section{$\underline{\text { References }}$}

1. J. A. E. Desa, A. C. Wright, J. Wong, and R. N. Sinclair, J. Non-Cryst. Solids 51, (1982) 57.

2. (a)S. Biggin and J. E. Enderby, J. Phys. C14, (1981) 3129; (b) D. A. Allen, R. A. Howe, N. D. Wood and W. S. Howells, to be published.

3. L. V. Woodcock, C. A. Angell and P. Cheeseman, J. Chem. Phys. 65, (1976) 1565.

4. P. A. V. Johnson, A. C. Wright and R. N. Sinclair, J. Non-Cryst. Solids 58, (1983) 109.

5. S. Susman, K. J. Volin, D. G. Montague and D. L. Price, J. Non-Cryst. Solids 123, (1990) 168 .

6. R. W. Johnson, S. Susman, and D. L. Price, J. Non-Cryst. Solids 75, (1985) 57; 83, (1986) $251 ; 88,(1986) 366$.

7. C. A. Angell, J. Non-Cryst. Solids 102, (1988) 205.

8. D. L. Price and J. M. Carpenter, J. Non-Cryst. Solids 92, (1987) 153; M. Arai, A. C. Hannon, A. D. Taylor, A. C. Wright, R. N. Sinclair ard D. L. Price, to be published.

9. U. Walter, D. L. Price, S. Susman and K. J. Volin, Phys. Rev. B37, (1988) 4232.

10. M. Arai, D. L. Price, S. Susman, K. J. Volin and U. Walter, Phys. Rev. B37, (1988) 4240 .

11. F. L. Galeener, J. C. Mikkelsen, A. C. Wright, R. N. Sinclair, J. A. E. Desa and J. Wong, J. Non-Cryst. Solids 42, (1980) 23.

12. F. L. Galeener, A. J. Leadbetter and M. W. Stringfellow, Phys. Rev. B27, (1983) 1052.

13. M. L. Cacciola, S. Magazu, P. Migliardo, F. Aliotta and C. Vasi, Solid State Comm. 57, (1986) 513.

14. C. A. Angell, G. H. Wegdam and J. Van der Elsken, Spectrochimica Acta 30A, (1974) 665; C. A. Angell and J. Wong, J. Chem. Phys. 53, 2053 (1970).

15. P. N. Sen and M. F. Thorpe, Phys. Rev. B15, (1977) 4030. 
TABLE 1. Characteristics of tetrahedrally coordinated $\mathrm{AX}_{2}$ glass formers

$\mathrm{AX}_{2} \quad$ Ref. $^{\mathrm{a}} \quad$ Ref. $^{\mathrm{b}} \quad \frac{\bar{b}_{\mathrm{A}}{ }^{\mathrm{c}}}{\bar{b}_{\mathrm{x}}} \quad \frac{M_{\mathrm{A}}{ }^{\mathrm{d}}}{M_{x}} \quad \theta^{\mathrm{e}} \quad \theta_{\mathrm{c}}{ }^{\mathrm{f}}$

$\begin{array}{llclllr}\mathrm{SiO}_{2} & 4 & 8 & 0.71 & 1.76 & 150^{\circ} & 112^{\circ} \\ \mathrm{ZnCl}_{2} & 1 & \text { This work } & 0.59 & 1.84 & 110^{\circ} & 111^{\circ} \\ \mathrm{GeSe}_{2} & 5 & 9 & 1.03 & 0.92 & 80-100^{\circ} & 136^{\circ} \\ \mathrm{SiSe}_{2} & 6 & 10 & 0.52 & 0.36 & 70^{\circ} & >180^{\circ}\end{array}$
a Reference to neutron diffraction
b Reference to inelastic neutron scattering
c Ratio of neutron scattering lengths
d Ratio of atomic masses
e Average bond angle $\mathrm{A}-\hat{\mathrm{X}}-\mathrm{A}$
f Critical angle $\theta_{c}=\cos ^{-1}\left(-2 \mathrm{M}_{\mathrm{x}} / 3 \mathrm{M}_{\mathrm{A}}\right)$ (Ref. 15). 


\section{FIGURE CAPTIONS}

FIGURE 1. Elastic scattering $\langle\mathrm{S}(\mathrm{Q}, \mathrm{O})\rangle$ for (a) vitreous and (b) liquid $\mathrm{ZnCl}_{2}$. Curve (a) is displaced vertically by 100 units. The solid lines through the symbols represent cubic spline fits to the data.

FIGURE 2. One-phonon effective vibrational density of states $G_{1}(E)$ for vitreous $\mathrm{ZnCl}_{2}$.

FIGURE 3. Effective vibrational density of states $\mathrm{G}(\mathrm{E})$ for liquid $\mathrm{ZnCl}_{2}$.

FIGURE 4. Scattering function $<\mathrm{S}(\mathrm{Q}, \mathrm{E})>$ for vitreous $\mathrm{ZnCl}_{2}$ measured at $\mathrm{E}=15.9 \mathrm{meV}$ (symbols), compared with model calculations for the $v_{4}$ mode (dashes). The solid line through the symbols represents a smooth cubic spline fit to the data.

FIGURE 5. Scattering functions $\angle \mathrm{S}(\mathrm{Q}, \mathrm{E})>$ for vitreous $\mathrm{ZnCl}_{2}$ measured at $\mathrm{E}=35.6 \mathrm{meV}$ (symbols), compared with model calculations for the $v_{3}$ model (dashes). The notation is the same as for Fig. 4. 


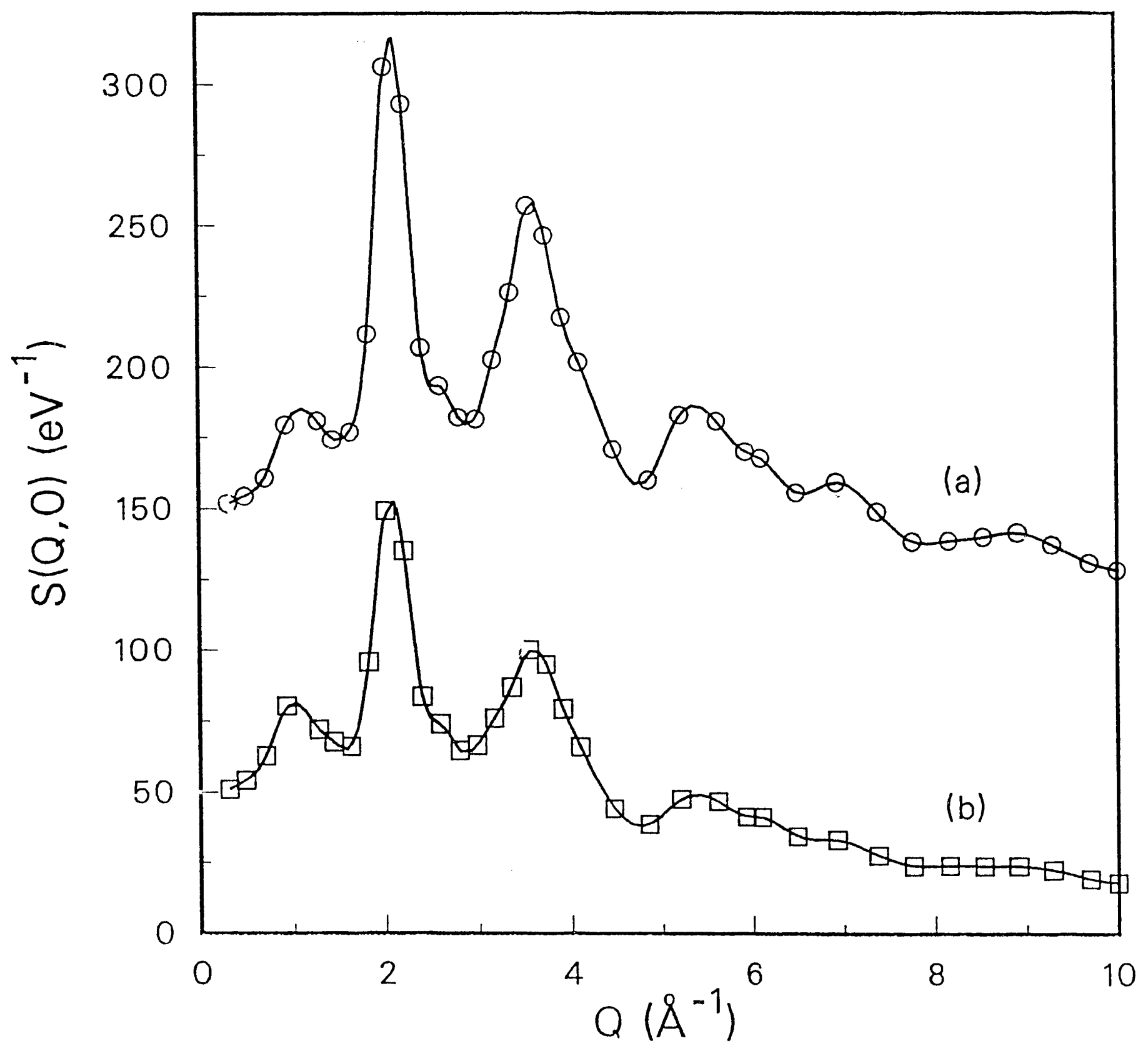




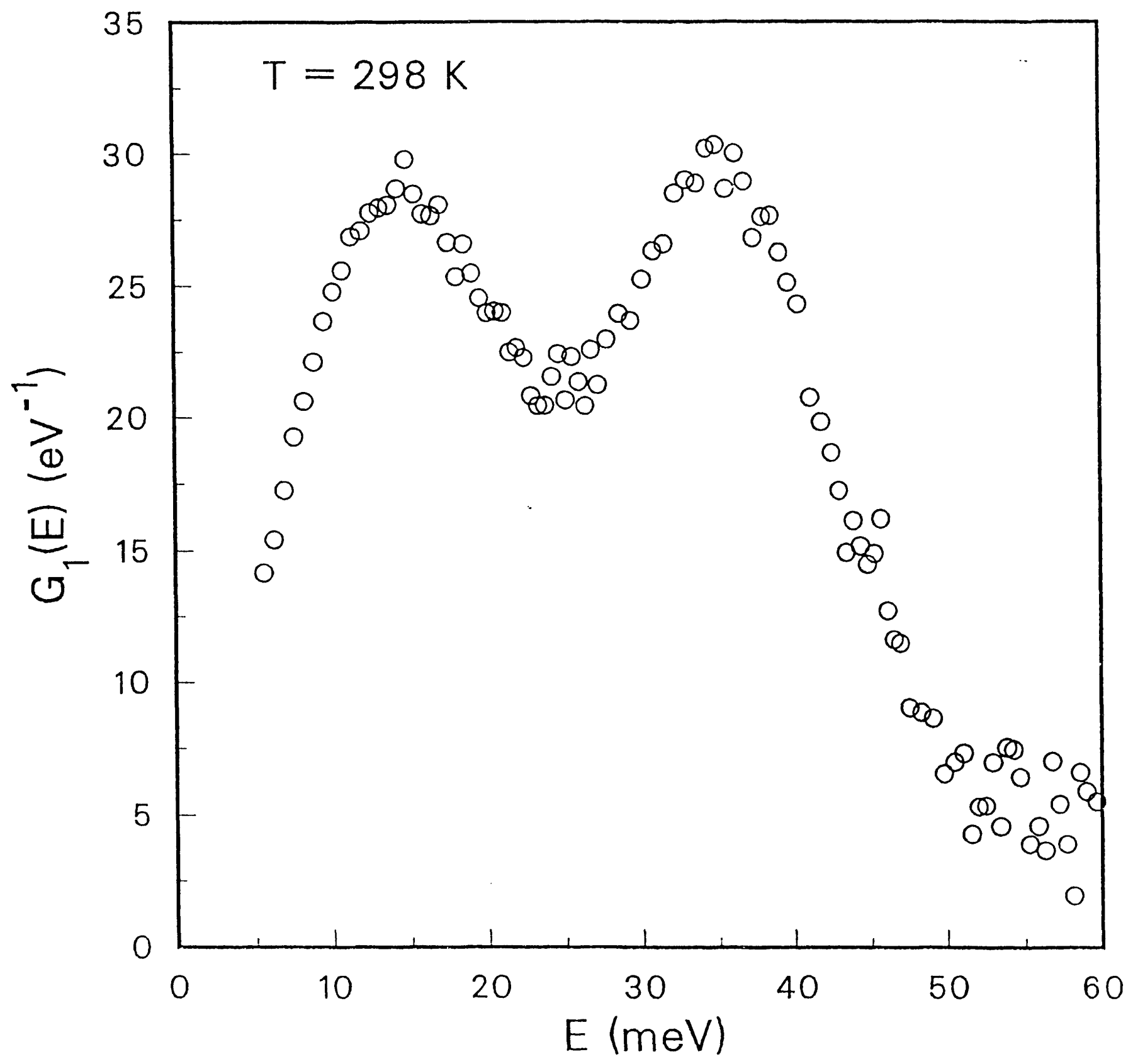

Druect of tan 2 


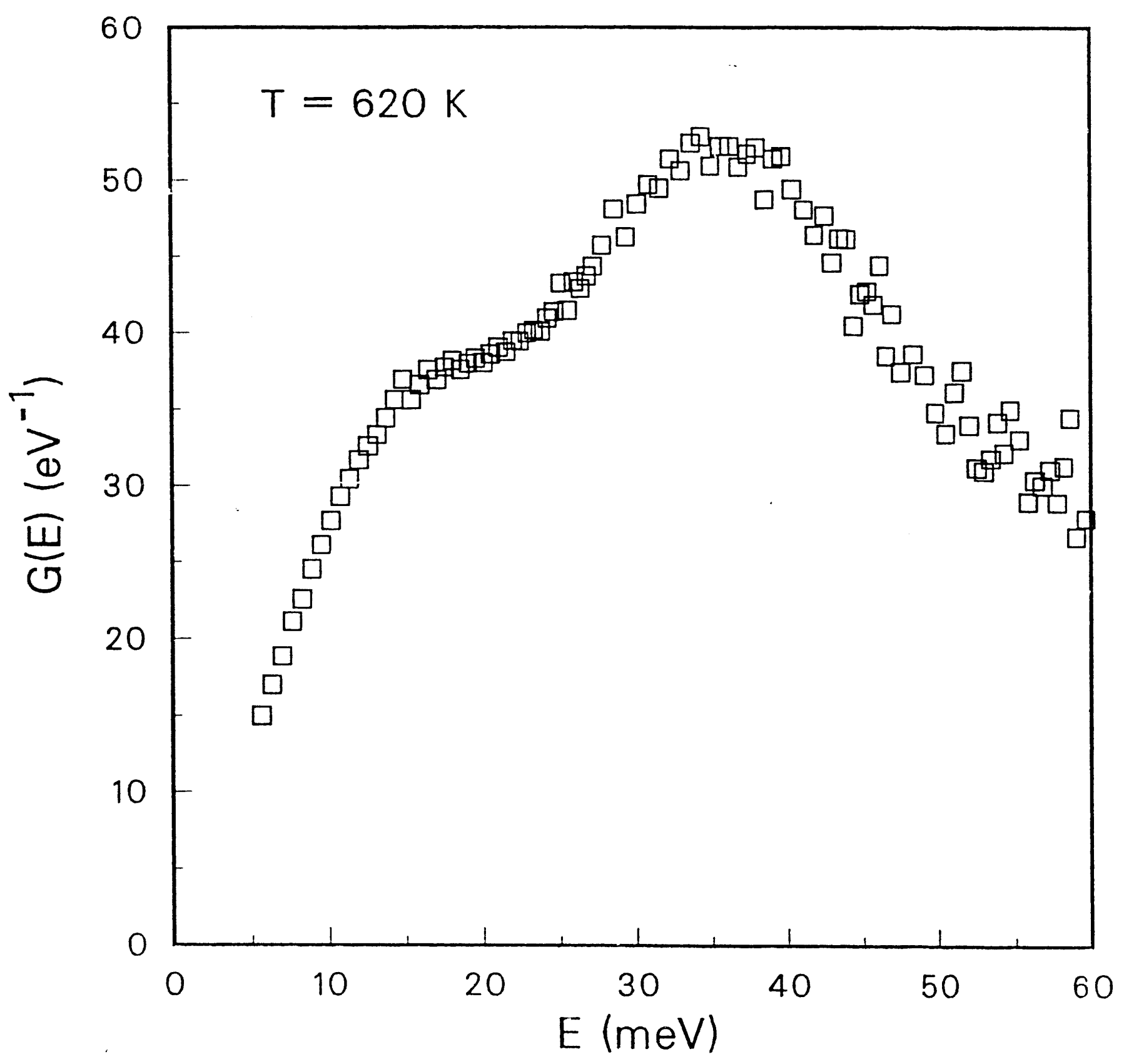

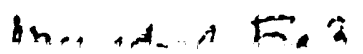




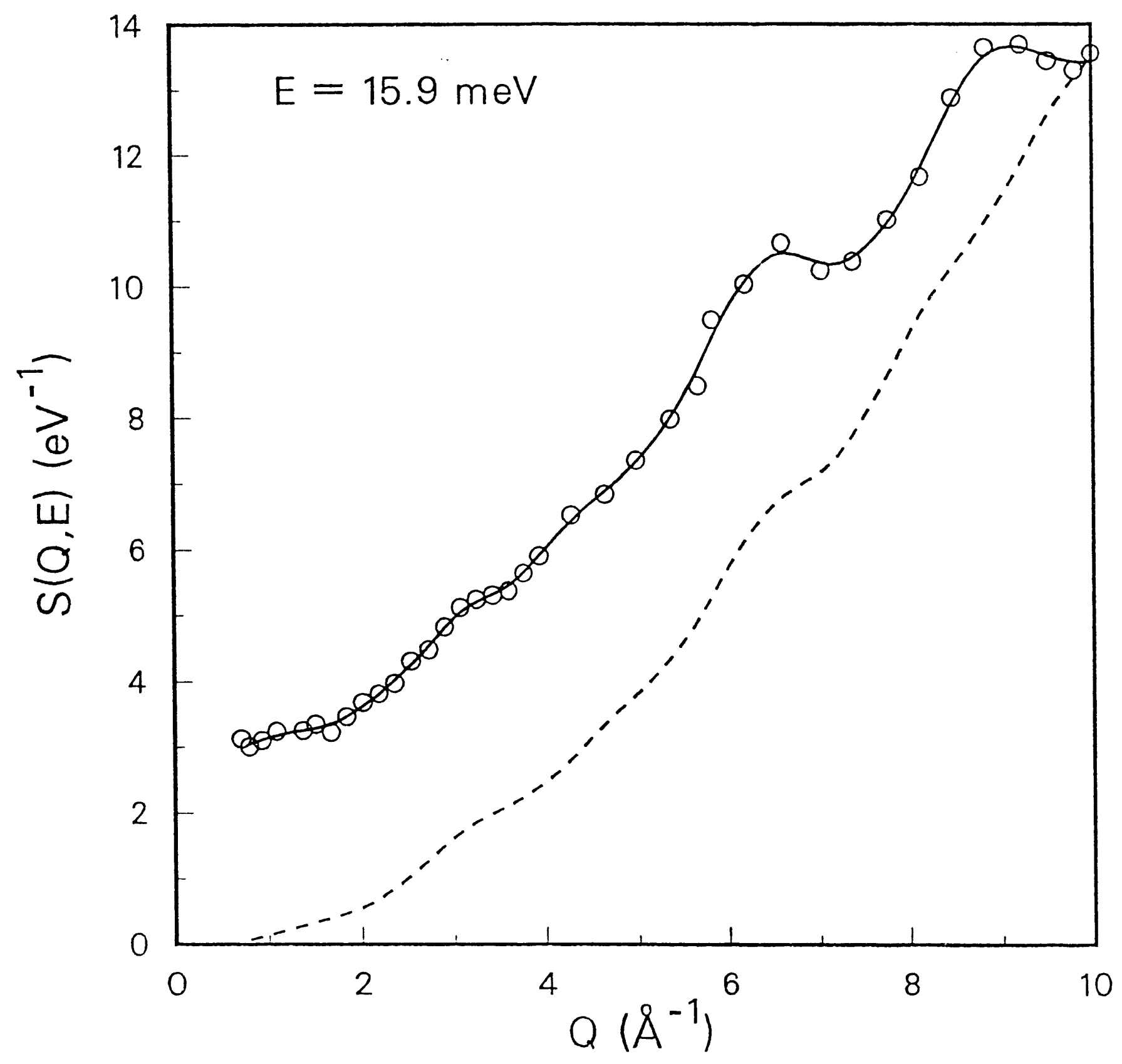




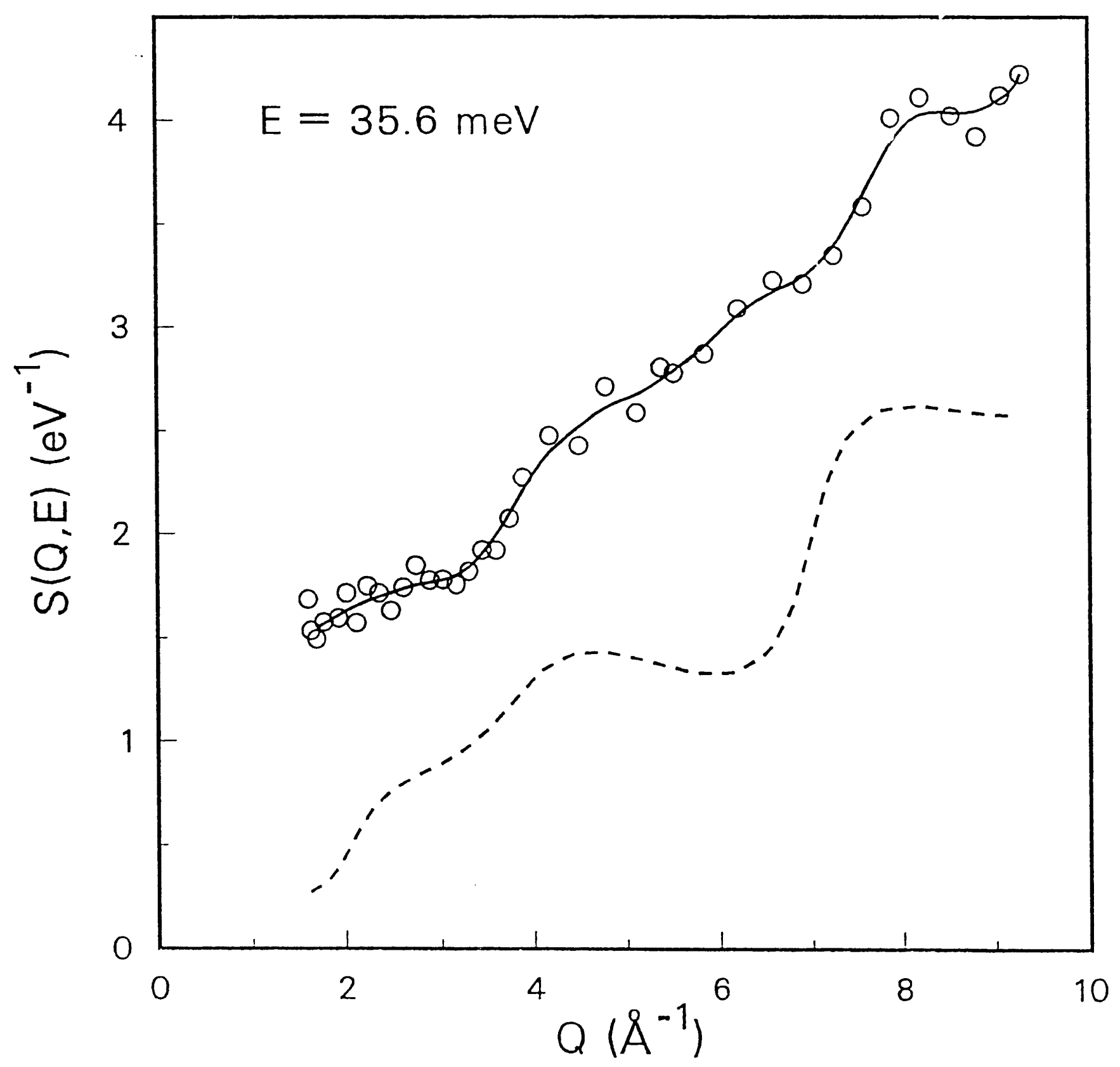



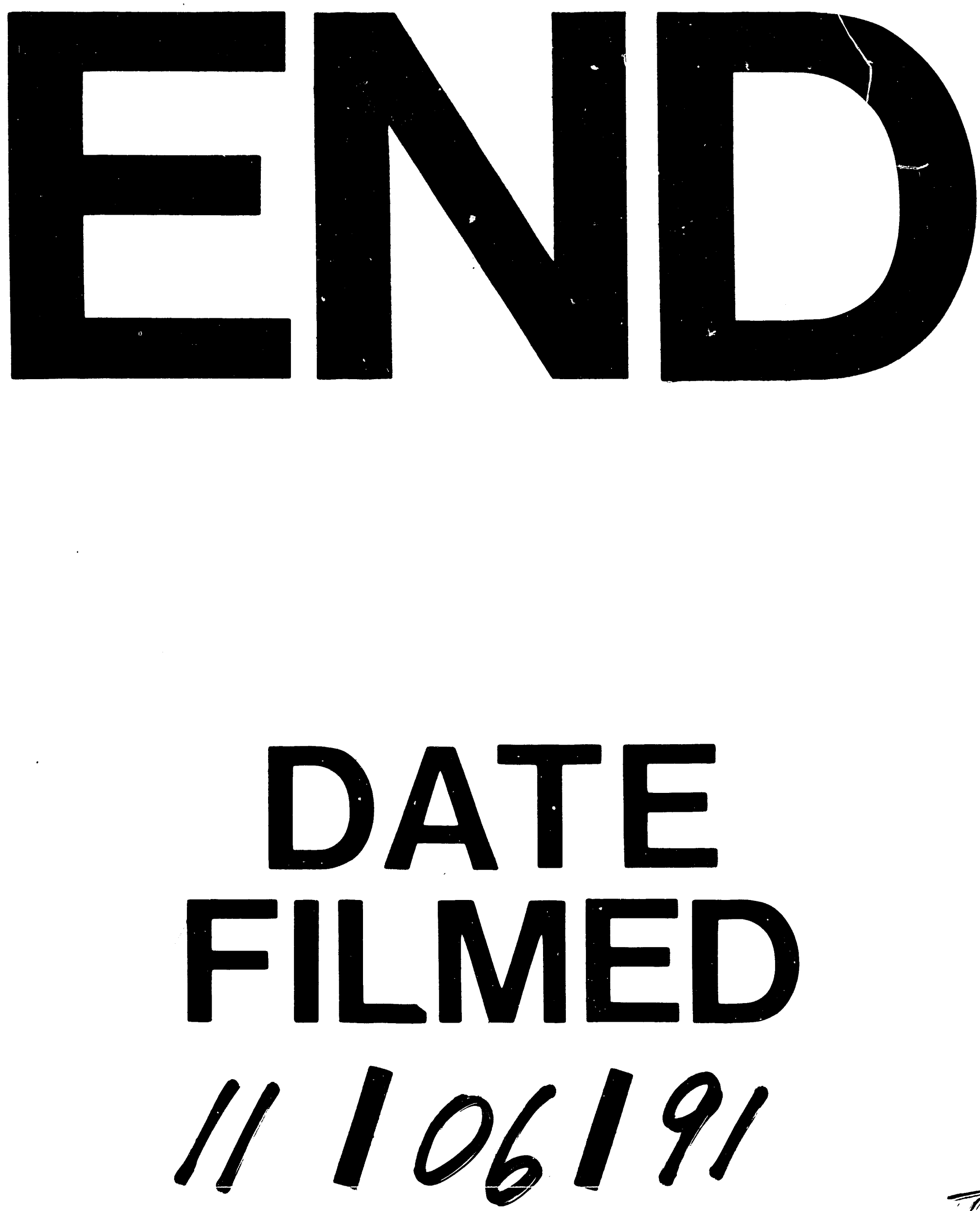
